\title{
Fratografia em vidros
}

\section{(Fractography in glasses)}

\author{
J. M. F. Coelho, C. A. Costa, M. Ferreira \\ PEMM/COPPE - Universidade Federal do Rio de Janeiro \\ Centro de Tecnologia Bl. F/210 \\ Rio de Janeiro, RJ 21949-900
}

\begin{abstract}
Resumo
A análise da superfície de fratura é um método extremamente confiável para se identificar as razões da falha em um material, uma vez que o caminho percorrido pela trinca fornece informações importantes sobre sua origem e direção de propagação, além das distribuições de tensões no momento da fratura, as causas de sua iniciação, a interação da trinca com a microestrutura e a sequiência de propagação da mesma. Nos vidros e cerâmicos, as principais características morfológicas da superfície de fratura são a origem, o espelho de fratura, a região de névoa ou bruma ("mist") e a região de ramificação de trincas ("hackle"). Além destas características, outras marcas importantes podem ocorrer na superfície de fratura de vidros, tais como: linhas de "Wallner", escarpas de aceleração e desaceleração, ramificações de rotação ("twist hackle"), asas de gaivotas ("gull wings") e os rastros de ramificação ("wake hackle"). As características morfológicas descritas são bem definidas nos vidros, uma vez que estes materiais são homogêneos, isotrópicos e não possuem cristais que interfiram com a propagação da trinca.
\end{abstract}

Palavras-chave: fratografia, vidros, superfície de fratura.

\section{INTRODUÇÃO}

A deformação dos materiais cristalinos pode variar de extrema fragilidade a extrema ductilidade. A quantidade de deformação é função do tipo de ligação atômica (metálica, iônica ou covalente), da estrutura cristalina (cúbica, hexagonal, romboédrica, etc.), da microestrutura presente (tamanho de grão, precipitação, densidade de discordâncias móveis, etc.), das condições de ensaio (tipo e taxa de carregamento, temperatura, meio ambiente, etc.) e do estado de tensão presente. De forma geral, os materiais metálicos apresentam bastante ductilidade, enquanto os cerâmicos são inerentemente frágeis. No entanto, em ambos materiais a morfologia de fratura é função da interação da trinca com a microestrutura presente [1].

Os vidros, típicos materiais amorfos, não possuem ordenação de longo alcance; logo não são formados por cristais [1]. A conseqüência imediata desta ausência de cristalinidade é que não há mecanismos de deformação plástica que gerem ductilidade

\begin{abstract}
Fracture surface analysis is a very reliable method to identify the causes of a material failure, since the crack propagation path allows the identification of the crack origin and the propagation direction, the stress state at the moment of the fracture, the causes of fracture initiation, interaction of the crack with the microstructure and the crack propagation sequence. In glasses and ceramics, the most important morphologic features of the fracture surface are the fracture origin, the fracture mirror, the mist and the hackle. Along with these fracture marks, other important surface features can be present too, for instance: "Wallner" lines, scarps, twist hackle, gull wings and the wake hackle. The above fracture surface features are very well defined in glasses, since these materials are homogeneous, isotropic and do not have a crystal structure that can interfere with the crack propagation.
\end{abstract}

Keywords: fractography, glasses, fracture surface. macroscópica abaixo da temperatura de transição vítrea $(\mathrm{Tg})$, tornando estes materiais eminentemente frágeis. Consequentemente, o alívio de tensões destes materiais é feito através de fratura, onde a mesma se propaga na direção normal à direção da tensão principal, segundo a lei da tensão normal [2].

Falha é a situação na qual um componente não pode mais desempenhar a função para a qual foi projetado. As falhas podem ocorrer devido a um projeto deficiente, má utilização do componente, defeito do material utilizado, falta de conhecimento das condições de serviço e outros mais. O conhecimento das causas que levam a uma falha é de extrema importância para o aprimoramento do projeto, tanto do ponto de vista do componente como do material.

Quando a falha é proveniente da fratura do material, a análise da superfície fraturada é um método extremamente eficiente na prevenção de novas falhas e no estudo das causas da mesma, pois a observação macroscópica e microscópica da fratura fornece 
informações sobre a origem e as causas da iniciação, direção e seqüência de propagação, sua interação com a microestrutura, além do estado de tensão no momento da fratura [2, 3]. Desta forma, o exame fratográfico possibilita que futuras falhas venham a ser eliminadas.

A interação de um defeito com a microestrutura do vidro resulta em características morfológicas bem definidas, as quais serão vistas neste trabalho. Cerâmicas cristalinas também podem apresentar as característica a serem observadas, porém nem sempre tão bem definidas.

\section{MORFOLOGIA DA SUPERFÍCIE DE FRATURA}

O exame da superfície de fratura normalmente deve seguir uma seqüência. Um dos primeiros passos na análise fratográfica é a reconstrução da peça, para que macroscopicamente se observe o local de origem da fratura. É importante ressaltar que a superfície de fratura não deve ser friccionada/tocada, a fim de se manter a sua integridade. Após a remontagem da peça, é necessário se identificar os lugares onde um grupo de trincas se encontram ou onde uma única trinca se ramifica, pois estas regiões serão os locais de início da fratura. A localização da origem da fratura deve ser feita com baixo aumento (binocular ou microscópio estereoscópio) ou simplesmente com observação visual. Após essa primeira observação, pode-se, caso necessário, fazer observações por microscopia ótica ou eletrônica de varredura. Algumas vezes, técnicas especiais podem ser necessárias, como por exemplo a réplica da superfície de fratura [2, 3].

A remontagem da peça fraturada permite visualmente a identificação rápida e segura do estado de tensão presente, pois existe uma relação direta entre o ângulo de ramificação das trincas e o tipo de carregamento que causou a fratura do vidro [1], conforme mostra a Fig. 1. Observa-se, também, que quanto maior a energia disponível para a fratura maior será o número de ramificações da trinca.

As características morfológicas mais importantes da superfície de fratura em vidros são a origem da fratura, o espelho de fratura, a região de névoa ou bruma ("mist") e a região de ramificação das

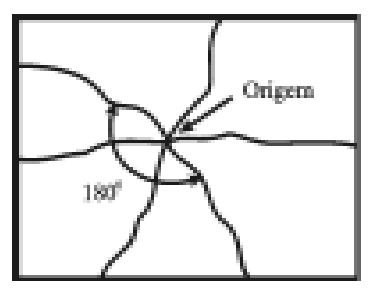

DMPACTD

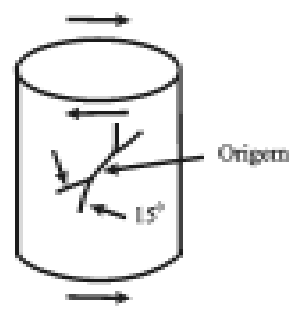

TORC̄̃o

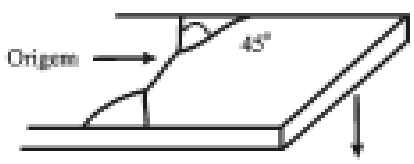

FLEXß̊o

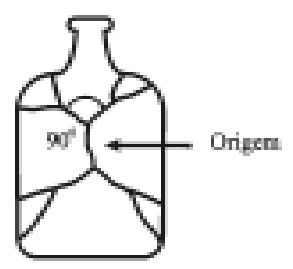

PRESSĀO INTTEXNA
Figura 1: Relação existente entre o ângulo de ramificação das trincas e o tipo de carregamento que causou a fratura. (a) Impacto; (b) Flexão; (c) Torção; (d) Pressão interna.
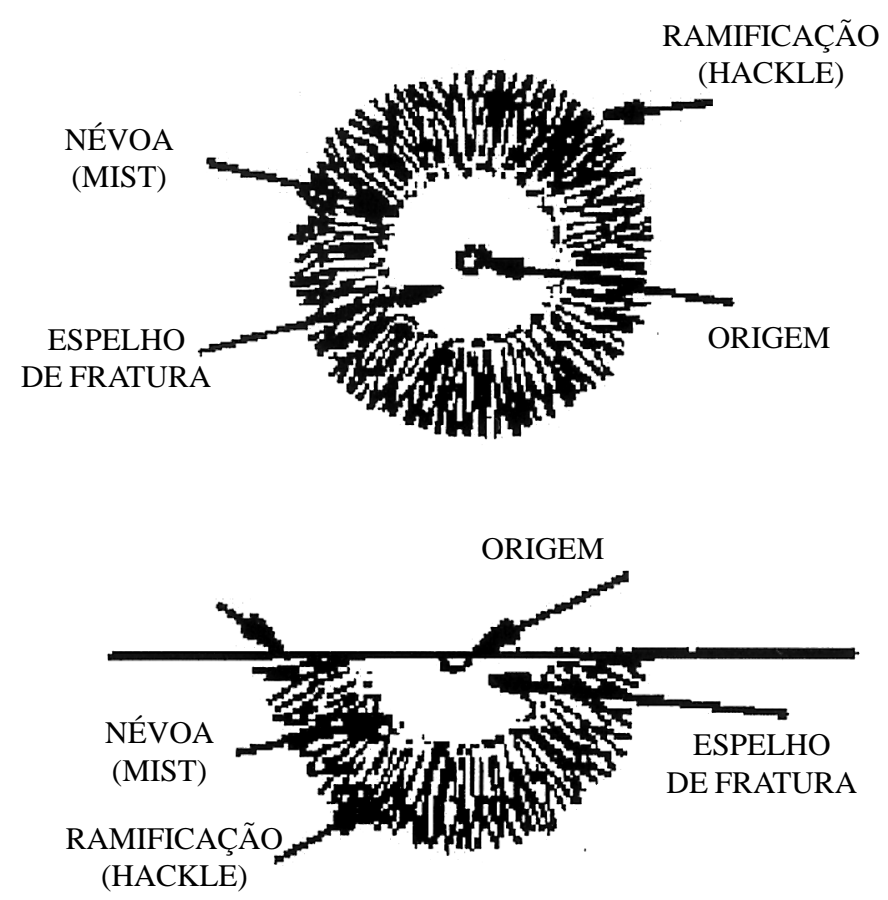

Figura 2: Representação esquemática de uma fratura típica em vidros. (a) Fratura com início no interior do vidro; (b) Fratura com início na superfície do vidro.

trincas ("hackle") [2, 4], conforme mostra a Fig. 2. Estas características são uma decorrência da interação entre a trinca que se propaga com o material, com os campos de tensões atuantes na peça e com as ondas acústicas provenientes da propagação da trinca.

A origem da trinca identifica o local a partir do qual propagouse toda a fratura e, por esta razão, é uma das características mais importantes da superfície de fratura. A origem da trinca tem lugar, prioritariamente, em defeitos preexistentes ou formados (poros, bolhas, pequenas trincas, etc.), que concentram tensões [3]. Estas tensões em determinado momento excedem a tensão de ruptura do material, ocasionando o início da fratura. Nos vidros, trincas de superfície são facilmente geradas por contato mecânico ou abrasão da superfície, sendo pontos muito comuns do início da falha nestes materiais [2]. O contato localizado gera alta tensão elástica confinada a uma área restrita. Quando uma tensão superior à tensão de ruptura do material é alcançada cria-se um defeito na superfície, isto é, uma trinca. A trinca criada concentra a tensão aplicada, levando à falha catastrófica do material [2]. O ponto de início da fratura situa-se no centro do espelho de fratura.

O espelho de fratura é a região onde a trinca é acelerada e caminha em um único plano, com velocidade ainda muito baixa, formando uma superfície plana e lisa que lembra um espelho. $\mathrm{O}$ raio do espelho de fratura $\left(\mathrm{R}_{\mathrm{m}}\right)$ e a sua forma dependem das características do material, das tensões locais na origem da fratura no momento da fratura e do tempo de fratura $[2,3,5]$. Um exemplo da influência do estado de tensões na formação do espelho de fratura pode ser claramente verificado em vidros cuja superfície está submetida a compressão. Neste caso, o raio do espelho de fratura tende a ser maior do que nos vidros cuja superfície não se encontra neste estado de tensão [6]. O motivo é que as tensões compressivas da superfície retardam a aceleração da trinca e, consequentemente, a sua passagem para a região de névoa e de ramificação também é retardada. 
A tensão na origem da fratura pode ser relacionada com o raio do espelho de fratura pela equação A [2]:

$$
\ln \sigma_{\mathrm{f}}+1 / 2 \ln \mathrm{R}_{\mathrm{m}}=\mathrm{A}
$$

Onde $\sigma_{\mathrm{f}}$ é a tensão de fratura, $\mathrm{R}_{\mathrm{m}}$ é o raio do espelho de fratura e A é uma constante.

Sendo o raio do espelho de fratura facilmente mensurável, podese realizar uma série de experimentos e determinar-se a constante "A" de um certo material. Outro fato importante é que, normalmente, a tensão de fratura de um dado material é obtida pela teoria de Griffith, onde é necessário conhecer-se precisamente o tamanho do defeito crítico, isto é, a origem da fratura. Muitas vezes, entretanto, a determinação do tamanho do defeito crítico é prejudicada, uma vez que, na maioria dos casos, este defeito não é simétrico e o seu contorno não é muito bem delimitado. Além disso, se o defeito for uma inclusão, a energia de fratura no contorno desta pode estar reduzida em relação ao restante do material. Assim, a determinação da tensão de ruptura para vidros a partir do raio do espelho de fratura é bastante precisa, pois neste caso o raio do espelho de fratura é simétrico e possui um tamanho muito maior do que o do defeito crítico [2, 3]. Apesar disto, a realização dos dois métodos em conjunto, associado a um criterioso julgamento de engenharia, é sempre bem visto para a determinação da tensão de fratura e das causas da falha do material.

A região de névoa forma-se quando a trinca atinge uma certa velocidade ou intercepta uma inclusão ou encontra uma mudança na direção das tensões principais, fazendo com que se desvie do seu plano original de propagação, formando pequenos sulcos radiais na superfície de fratura [7, 8]. Este desvio resulta na formação de uma superfície com aspecto rugoso, semelhante à da névoa formada por uma queda d'água.

No caso do desvio do plano original devido ao aumento da velocidade, isto ocorre quando a trinca atinge entre $1 / 2$ e $2 / 3$ da velocidade característica $\left(\mathrm{V}_{\mathrm{c}}\right)$, que é a velocidade de propagação de ondas transversais no material. Consequentemente, a disponibilidade de grande quantidade de energia durante a fratura resultará em um

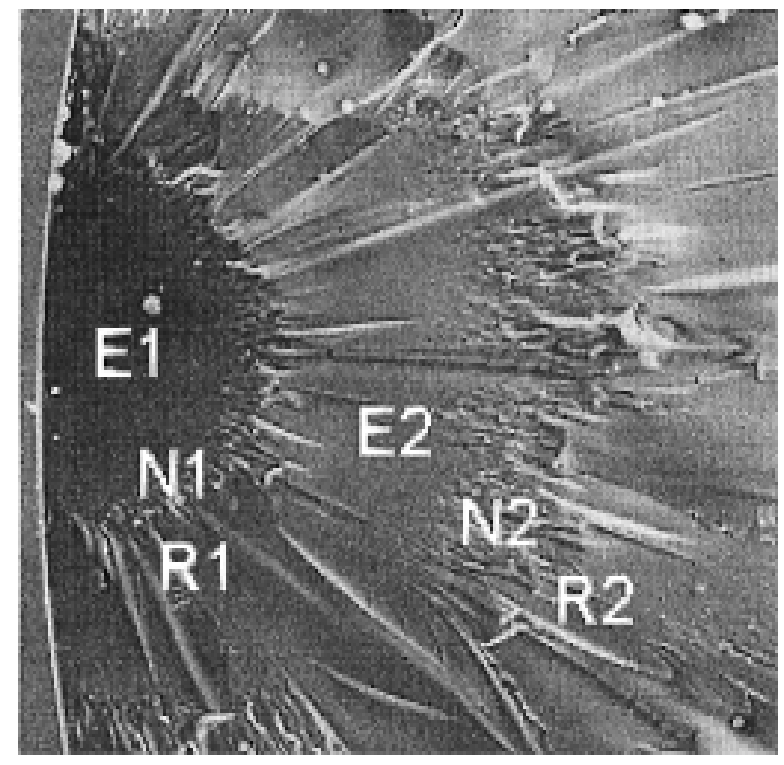

Figura 3: Observação no MEV da superfície de fratura de um bastão de vidro submetido à flexão (Mag. X47) [2]. menor espelho de fratura, pois mais rapidamente a trinca atingirá os valores necessários para que se desvie do plano original [9].

A região de ramificação das trincas é o estágio seguinte à região de névoa, onde a trinca original sofre várias bifurcações. A quantidade de ramificações também fornece informações qualitativas sobre a quantidade de energia disponível durante a fratura, pois quanto maior a energia disponível, maior será o número de ramificações.

Exemplo das regiões supracitadas pode ser observado na Fig. 3, que mostra a superfície de fratura de um bastão de vidro submetido à flexão. A origem da fratura é a esquerda $(\mathrm{O})$; a região semicircular lisa é o espelho de fratura $\left(\mathrm{E}_{1}\right)$, a qual é circundada pela região de névoa $\left(\mathrm{N}_{1}\right)$ e pela região de ramificação de trincas $\left(\mathrm{R}_{1}\right)$. Observa-se também, nesta figura, a formação de um segundo espelho de fratura $\left(\mathrm{E}_{2}\right)$, uma segunda região de névoa $\left(\mathrm{N}_{2}\right)$ e de ramificação $\left(\mathrm{R}_{2}\right)$. A formação desta segunda região é devido à redução momentânea da velocidade das trincas ramificadas em $\mathrm{R}_{1}$, formando um novo espelho de fratura $\left(\mathrm{E}_{2}\right)$ e uma nova região de névoa $\left(\mathrm{N}_{2}\right)$, até ramificarem-se novamente formando $R_{2}$ [2]. Assim, a velocidade com que a trinca se propaga no material exerce uma forte influência sobre a morfologia da fratura.

Outra característica bem definida da superfície de fratura de materiais vítreos são as linhas de "Wallner", esquematicamente representadas na Fig. 4. Estas são formadas durante o processo de fratura, quando ondas de som são produzidas no interior do material. Conforme cada frente de onda se sobrepõe à frente de propagação da fratura, a trinca momentaneamente desvia-se da direção da tensão principal. Após este desvio momentâneo, a frente de propagação de trinca retorna à direção original da tensão principal. Isto resulta em uma série de arcos na superfície de fratura, os quais são chamados de linhas de "Wallner" $[1,2,10]$. A curvatura de cada linha mostra a forma aproximada da frente da trinca no momento da interseção com a onda sônica e fornece tanto a direção de propagação da trinca quanto a distribuição das tensões. A direção de propagação é sempre do lado côncavo para o lado convexo das linhas de "Wallner", enquanto a distribuição de tensões é dada pela

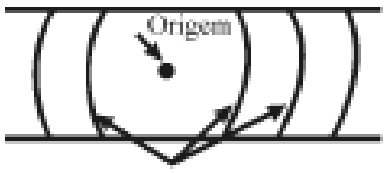

Linhas de "Wallner"

a) Traçîio Uniforme

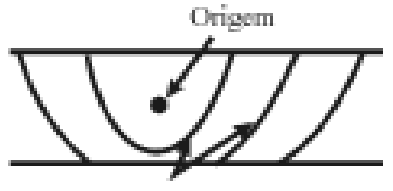

Linhas de "Wallner"

b) Traçīo Năo-Uniforme

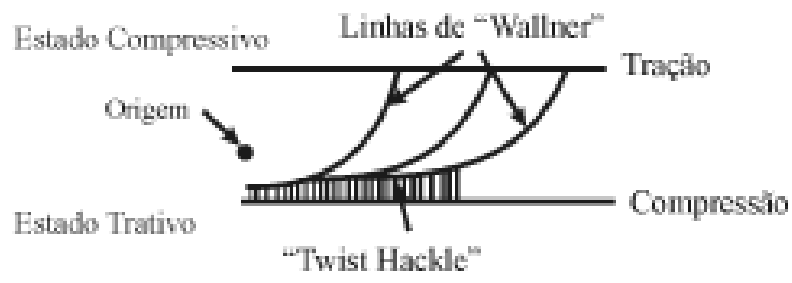

c) Flexâo

Figura 4: Representação esquemática das linhas de "Wallner" na superfície de fratura e a influência do estado de tensão presente na sua formação, tal que: (a) Tração uniforme; (b) Tração não uniforme; (c) Flexão (parte superior em tração e inferior em compressão). 


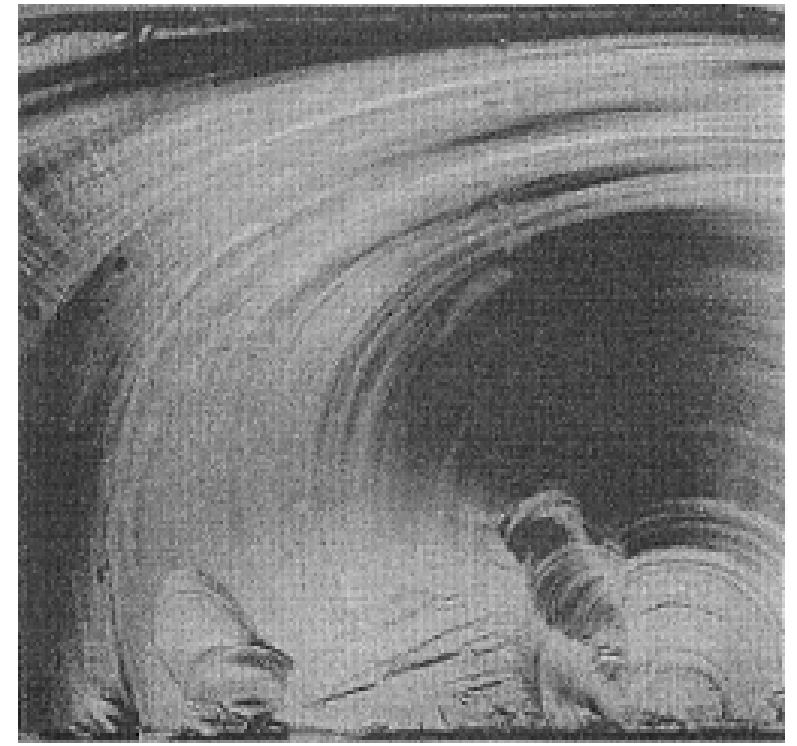

Figura 5: Superfície de fratura de um vidro submetido à impacto, onde se observa as linhas de "Wallner" na parte superior. Fratografia ótica [2] (Mag. X74).

distância entre a linha e a origem [2].

Exemplo prático das linhas de Wallner está apresentado na Fig. 5, onde se observa a superfície de fratura de um vidro submetido à impacto. No canto inferior esquerdo verifica-se a origem da fratura e na parte superior as linhas de "Wallner" [1].

Outra forma de ocorrência da região de ramificação é quando o campo de tensões sofre um giro, isto é, sofre rotação sobre o eixo normal à frente da trinca (paralelo à direção de propagação). Obedecendo à lei da tensão normal [2], a fratura tenderia a sofrer uma rotação; entretanto, esta condição de rotação é energeticamente pouco favorável para a frente da trinca como um todo. Ao invés de sofrer rotação, a frente da trinca se ramifica em uma série de frentes paralelas e não coplanares, chamadas de ramificação de rotação ("twist hackle"), que estão alinhadas com o novo eixo local de tensão principal. Inicialmente, estes segmentos individuais de fratura estão desconectados, porém, logo em seguida, eles se conectam formando a região de ramificação ("hackle") $[2,9]$.

Este fenômeno de ramificação devidoà rotação ("twist hackle") aparece na superfície de fratura como adagas muito estreitas e afiadas na forma de linhas paralelas, como mostrado na parte superior da Fig. 6. Esta figura mostra parte da superfície de fratura de uma placa de vidro submetida à flexão, onde a parte superior é a região de tensões compressivas e a inferior de tensões trativas. A direção geral de propagação foi da esquerda para a direita, como pode ser concluído a partir da curvatura das linhas de "Wallner" (visto na parte inferior da figura).

As ramificações de rotação não estão associadas à velocidade de propagação da trinca, pois mesmo em velocidades muito baixas, inferiores a $1 \mathrm{~m} / \mathrm{s}$, verifica-se o aparecimento das mesmas [10].

Em alguns vidros, trincas que se propagam a baixas velocidades podem ser afetadas pelo meio, em particular pela água ou vapor d'água. Se toda a frente da trinca está se propagando em um meio aquoso ou em vapor d'água, não há formação de marcas na superfície de fratura. A presença d'água retarda a propagação da trinca, ou parte dela que contém água, pelo efeito da viscosidade. Desta forma, se parte da frente da trinca é exposta a um meio úmido

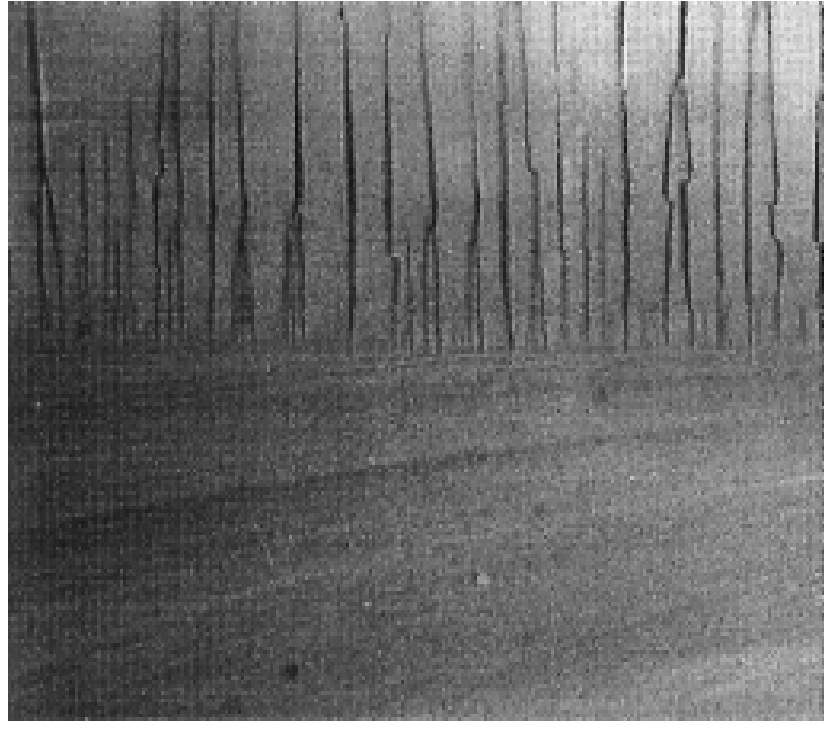

Figura 6: Superfície de fratura de uma placa de vidro submetida à flexão. As ramificações de rotação ("twist hackle") são vistas na parte superior da figura. Microscopia ótica (Mag. X50) [2]

e outra parte a um meio seco, aparece na superfície de fratura linhas chamadas de escarpas. Estas linhas são criadas na interseção dos dois meios, isto é, entre o seco e o úmido/molhado. As escarpas podem ser de dois tipos: escarpas de desaceleração e escarpas na forma de serra. As escarpas de desaceleração são formadas quando a frente da trinca que se propaga inicialmente em um meio seco tem sua velocidade reduzida pela ação da viscosidade da água, a qual é absorvida da superfície pela ação de capilaridade [1,2,11]. Desta forma, a frente da trinca úmida/molhada tem a sua velocidade reduzida em relação a parte central que continua seca. A desaceleração da trinca continua e a água penetra nas partes da trinca que ainda estavam secas e este processo prossegue até que toda a frente da trinca esteja umedecida. Estas linhas representam o local da frente da trinca entre o meio seco e o meio úmido.

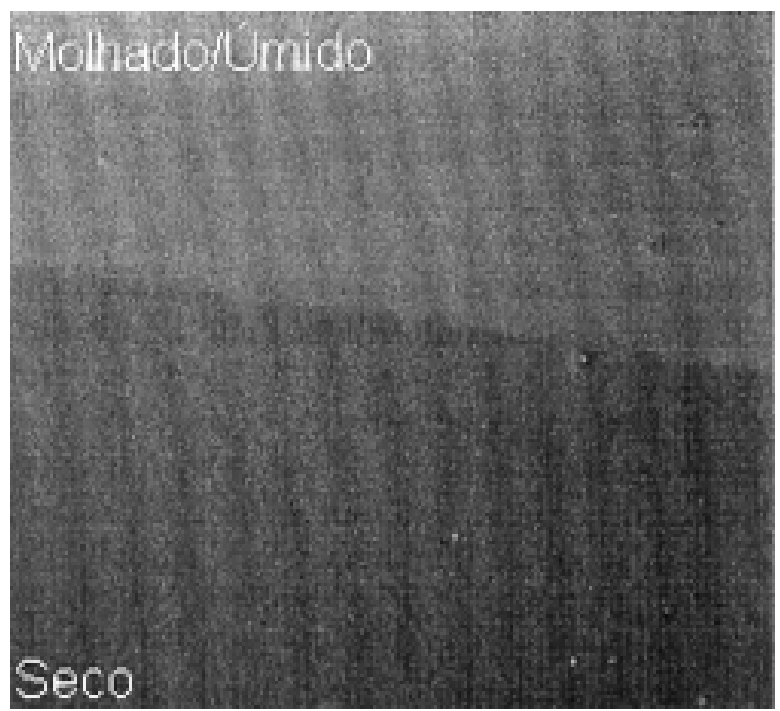

Figura 7: Escarpas de desaceleração na superfície de fratura de uma placa de vidro. Microscopia ótica (Mag. X45) [2]. 
A Fig. 7 mostra a escarpa de desaceleração na superfície de fratura de uma placa de vidro. As superfícies em contato com os meios úmido e seco são mostradas na parte superior e inferior, respectivamente, desta figura. A escarpa de desaceleração é a linha aproximadamente horizontal no centro da figura, enquanto as várias marcas verticais são as linhas de Wallner. A fratura propagou-se da esquerda para a direita, corroborando o aumento da área úmida da frente da trinca à medida que a mesma avançava.

As escarpas mais interessantes, entretanto, são formadas quando uma trinca que caminha em meio úmido é submetida a uma elevação e queda de tensão [2, 10-12], conforme mostrado na Fig. 8, as quais são chamadas de escarpas de serra. Este nome decorre do aparecimento na superfície de fratura de marcas semelhantes a picos de montanhas. Elas são formadas quando, na ausência de água na superfície livre, a trinca se acelera, cavita (muda abruptamente de velocidade, deixando a água para trás), desacelera e é alcançada pela água que vem atrás. Varner [2] atribui a morfologia deste tipo de fratura à água que não alcança toda a frente da trinca seca simultaneamente, mas como dedos que tocam partes da frente de propagação. Em cada uma dessas partes, a água assiste a propagação da trinca, causando uma curvatura à frente das porções secas. Estas partes curvas expandem-se quanto mais moléculas de água são associadas à elas, até que toda a frente da trinca passa de novo a caminhar em um meio úmido. Neste caso, aparecem escarpas na forma de serra no local do contorno entre a parte seca e úmida da frente da trinca. Como ocorrem múltiplas interações entre as porções de água e as frentes da trinca, uma escarpa formada move outra escarpa, criando uma linha com múltiplos picos. É igualmente plausível que este tipo de morfologia seja o resultado do seguinte processo: após a cavitação, grande parte da frente da trinca está em contato com a água e pequenas regiões estão secas (talvez pela própria cavitação do líquido). As partes molhadas sofrem uma forte desaceleração pela viscosidade da água, enquanto as parte secas voltam a sofrer um processo de aceleração ou cavitação localizada. O rápido crescimento das partes secas origina os picos agudos, enquanto os vales são formados pela trinca em contato com a água. Esta situação perdura até que a frente da trinca em contato com a água atinja a parte seca, onde a mesma passa crescer como uma frente única até que outro evento desta natureza ocorra.

Outro tipo de marca importante que pode ocorrer na superfície de fratura de vidros são as chamadas asas de gaivotas ("Gull Wings") e os rastros de ramificação ("Wake Hackle"). Estas marcas na superfície de fratura são provenientes das combinações de duas

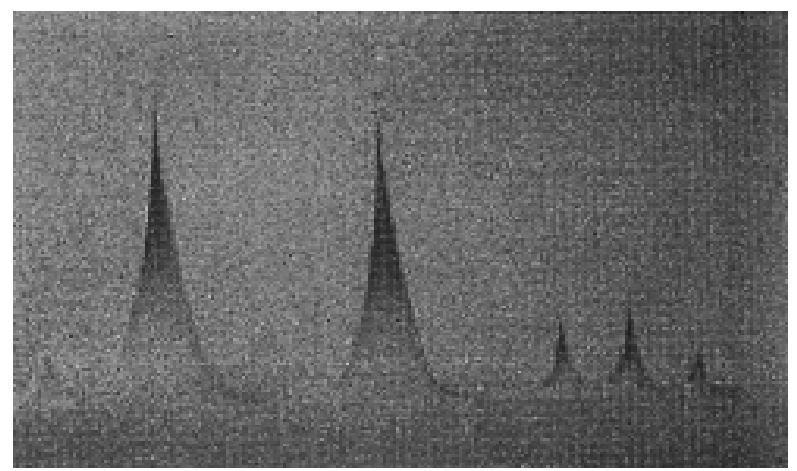

Figura 8: Superfície de fratura de uma placa de vidro, mostrando as escarpas em forma de serra. A direção de propagação da fratura é de baixo para cima. Microscopia ótica (Mag. X60) [2].

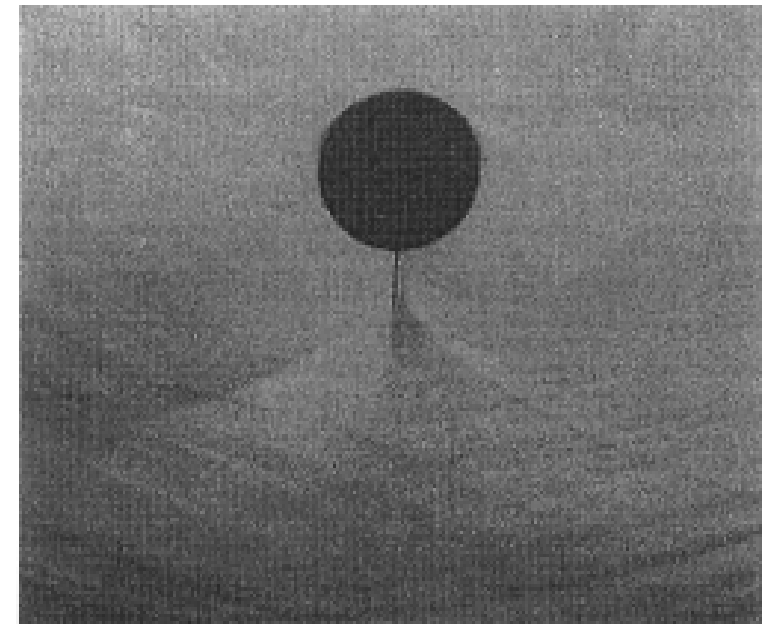

Figura 9: Superfície de fratura de um tubo capilar de vidro submetido à flexão. Verifica-se a formação das asas de gaivotas e do rastro de ramificação. Microscopia ótica (Mag. X50) [2].

outras marcas, as linhas de "Wallner" e as ramificações devido a rotação ("twist hackle") [2, 13]. A Fig. 9 mostra a superfície de fratura de um tubo capilar de vidro submetido à flexão. A fratura se propagou da parte superior para a inferior da figura, como verificase pela concavidade e interseção das linhas de "Wallner". O círculo preto é o furo do tubo capilar.

A marca logo abaixo do furo do tubo capilar é uma ramificação por rotação ("twist hackle"), neste caso chamada de rastro de ramificação. Verifica-se também a formação de duas fortes linhas de "Wallner" que se interceptam formando as asas de gaivotas. Estas marcas estão associadas a presença de inclusões nos materiais, como por exemplo: poros, bolhas e partículas sólidas que vão interferir na direção de propagação da frente de trinca. As marcas de asas de gaivotas e rastros de ramificação (algumas vezes chamados de cauda ("tail"), estão do lado oposto à origem da fratura $[2,9]$.

As asas de gaivotas e os rastros de ramificação são formados quando a frente da trinca encontra uma inclusão, poros ou bolhas, como já visto anteriormente. Entretanto, a trinca não passa, simplesmente, através do obstáculo, ela é forçada a circundá-lo. Como consequiência, a frente da trinca é bifurcada em duas novas frentes. Quando estas duas nova frentes de trincas se encontram no lado oposto do obstáculo, onde quase sempre não estão caminhando em um mesmo plano, elas se sobrepõem levemente e o material que as separa se fratura. Esta fratura gera pulsos sônicos que interagem com o movimento da frente de trinca, criando as marcas características de asas de gaivotas na superfície de fratura.

\section{CONCLUSÕES}

As características da superfície de fratura anteriormente descritas são muito bem definidas para os vidros, uma vez que estes materiais são homogêneos, isotrópicos e não possuem cristais que interfiram na propagação de trinca. A propagação da trinca é governada somente pelo estado de tensões, tempo de falha e tensões residuais (como aquelas induzidas por têmpera térmica e química). Desta forma, as marcas na superfície de fratura são vistas facilmente, sendo assim uma análise bastante importante para se concluir sobre o processo de fratura em vidros. 


\section{AGRADECIMENTOS}

Gostaríamos de agradecerà ASM International@e ao Dr.James R. Varner pela autorização da reprodução das fotografias utilizadas neste trabalho.

\section{REFERÊNCIAS}

[1] V. D. Fréchette, "Failure Analysis of Brittle Materials", Advances in Ceramics, The Am. Ceram. Soc. 28 (1990).

[2] J. R. Varner, "Descriptive Fractography, Ceramics and Glasses, Engineered Materials Handbook, The Materials Information Society, 14 (1991).

[3] T. A. Michalske, "Quantitative Fracture Surface Analysis, Ceramics and Glasses", Engineered Materials Handbook, The Materials Information Society, 4 (1991).

[4] V. D. Fréchette, J. R. Varner, "Fractography of Glasses and Ceramics", Advances in Ceramics, The Am. Ceram. Soc. 22 (1986). [5] V. D. Fréchette, J. R. Varner, "Fractography of Glasses and Ceramics II", Ceramic Transactions, The Am. Ceram. Soc. 17 (1991). [6] R. W. Rice, "Perspective on Fractography, Fractography of Glasses and Ceramics", V. D. Fréchette and J. R. Varner, The American Ceramic Society, (1986) 3-56.

[7] R. W. Rice, "Ceramic Fracture Features, Observations,
Mechanisms, and Uses", Fractography of Ceramic and Metal Failures, J. J. Mecholsky Jr. and S. R. Powell Jr., Ed., American Society for Testing and Materials, (1984) 5-103.

[8] R. W. Rice, "Fracture Topography of Ceramics", Surfaces and Interfaces of Glass and Ceramics, V. D. Fréchette, W. C. LaCourse, and V.L. Burdick, Plenum Press (1974) 439-472.

[9] V. D. Fréchette, "Fractology of Glass", Introduction to Glass Science, L. D. Pye, H. Stevens, and W. LaCourse, Ed. Plenum Press (1972).

[10] T. A. Michalske, "Dynamic Effects of Liquids on Crack Growth Leading to Catastrophic Failure in Glass", Ph.D. thesis, Alfred University (1979).

[11] V. D. Fréchette, "Markings Associated with the Presence of $\mathrm{H}_{2} \mathrm{O}$ During Cracking", Fractography of Glasses and Ceramics, Advances in Ceramics, V. D. Fréchette and J. R. Varner, The Am. Ceram. Soc. 22 (1986) 71-76.

[12] J. R. Varner, H. J. Oel, "Surface Defects: Their Origin, Characterization and Effects on Strength", J. Non-Cryst. Solids 19 (1975) 321-333.

[13] S. W. Freiman, "A Critical Evaluation of Fracture Mechanics Techniques for Brittle Materials", Fracture Mechanics of Ceramics, R. C. Bradt, A. G. Evans, D. P. A. Hassleman, and F. F. Lange, Plenum Press, 6 (1983).

(Rec. 06/08/99, Ac. 05/05/00) 